\title{
Deutsches Zentralkomitee zur Erforschung und Bekämpfung der Krebskrankheit.
}

Im vergangenen Jahre wurden in den Ausschuß gewählt:

Generaloberstabsarzt im Reichswehrministerium Prof. Dr. Schultzen,

Berlin W. 66, Leipzigerstr. 5.

Stadtmedizinalrat Prof. Dr. Drigalski, Berlin C. 2, Rathaus.

Staatsminister Dr. Schmidt-Ott, Präsident der Notgemeinschaft der Deutschen Gesellschaft, Berlin, Schloß.

Als Mitglieder wurden in dem Verzeichnis versehentlich fortgelassen:

Regierungspräsident Dr. Kruse, Godesberg/Rhein.

Dr. Henri Hirsch, Altona.

Dr. med. Moses, Mitglied der preußischen Nationalversammlung.

Geh. Sanitätsrat Dr. Rabnow, Stadtmedizinalrat a. D., Berlin W. 30, Schwäbischestr. 6 .

Neugewählt als Mitglieder:

Dr. Thies, Leipzig.

Oberreg.-Med.-Rat Prof. Dr. Otto Strauss, Berlin N. 4, Kesselstr. 19.

Bayerischer Landesverband.

Sitz: München, Pettenkoferstr. 8a.

1. Vorsitzender: Geh. Med.-Rat Prof. Dr. Max Borst.

2. Vorsitzender: Geh. Med.-Rat Prof. Dr. Leo von Zumbusch.

1. Schriftführer: Dr. Mertens.

2. Schriftführer: Sanitätsrat Dr. Christoph Müller.

Schatzmeister: Dr. Heinrich Martin, Bankhaus Martin \& Co. 